\title{
Usefulness and Limitation of Measurement of Insulin-Like Growth Factor Binding Protein-3 (IGFBP-3) for Diagnosis of Growth Hormone Deficiency
}

\author{
Yukiniro HASEGAWA, TомоNobu HASEGAWA, TaIji ASO, \\ SHinobu KOTOH, Yutaka TSUCHIYA, OSAMU NOSE*, \\ Yoshinide OHYAMA**, Kumiko ARAKI***, Toshiaki TANAKA****, \\ Sumitaka SAISYO ${ }^{\dagger}$, Susumu YOKOYA ${ }^{\dagger \dagger}$, Yoshikazu NISHI ${ }^{\dagger \dagger \dagger}$, \\ Shigeki MIYAMOTO ${ }^{\dagger+\dagger}$, Nozomu SASAKI ${ }^{\dagger \dagger \dagger}$, AND Mark STENE ${ }^{*}$ \\ Division of Endocrinology and Metabolism, Tokyo Metropolitan \\ Kiyose Children's Hospital, Tokyo 204, *Nose Clinic, Osaka 530, \\ **Department of Pediatrics, Kitasato University School of \\ Medicine, Kanagawa 228, ***Department of Pediatrics, Kochi \\ Medical School, Kochi 781-51, ****National Children's \\ Hospital, Tokyo 154, ${ }^{\dagger}$ Department of Pediatrics, Tokyo Medical \\ and Dental University, Tokyo 113, ${ }^{\dagger \dagger}$ Department of Pediatrics, \\ Toranomon Hospital, Tokyo 105, ${ }^{1+\dagger}$ Department of Pediatrics, \\ Hiroshima Red Cross Hospital, Hiroshima $730,{ }^{\dagger+\dagger}$ Division of \\ Endocrinology, Chiba Prefectural Children's Hospital, Chiba \\ 280-02, Japan, and ${ }^{*}$ Endocrine Sciences, Peptide Hormone \\ Section, CA 91301, USA
}

\begin{abstract}
To analyze the utility of insulin-like growth factor binding protein-3 (IGFBP-3) radioimmunoassay for diagnosis of growth hormone deficiency (GHD) we measured IGFBP-3 in sera from normal children, short children and patients with GHD. The sensitivity (true positive ratio) of IGFBP-3 for complete GHD (cGHD) was $93 \%$, while the specificity (true negative ratio) for normal short children (NS) was $88 \%$. In contrast, the sensitivity of IGFBP-3 for partial GHD (pGHD) was only $43 \%$. The poor discrimination between patients with pGHD and NS may be the result of their relatively similar GH level, as compared to cGHD, or due to the limitations of GH stimulation tests. The specificity of IGFBP-3 for NS was excellent in children of all ages: less than 10 years old $(87 \%)$ and older than $10(88 \%)$. However, sensitivity for GHD was good for children less than 10 years old $(84 \%)$ but poor for children older than $10(64 \%)$. IGFBP-3 may be less sensitive for diagnosing GHD in older children because IGFBP-3 levels may also increase during puberty due to mechanisms independent of the GH-IGF-I axis.
\end{abstract}

Key words: IGFBP-3, GH, Growth hormone deficiency (GHD), Normal short children (NS).

(Endocrinol Japon 39: 585-591, 1992)

THE INSULIN-like growth factors I and II (IGFs), important growth factors both in vivo and in vitro [1, 2], are known to have at least six binding proteins (IGFBP-1 6) [3, 4]. In human serum,

Received: July 9, 1992

Accepted: October 3, 1992

Correspondence to: Dr. Yukihiro HASEGAWA, Division of Endocrinology and Metabolism, Tokyo Metropolitan Kiyose Children's Hospital, 1-3-1 Umezono, Kiyose 204, Japan. four IGFBPs (IGFBP-1 4) are reported to exist[5, 6]. Among them, IGFBP-3 is a major binding protein in serum and is considered to be GH-IGFI axis dependent [6, 10].

When IGFBP-3 was analyzed by western ligand blot, Cohen and Rosenfeld et al. reported that there was some overlap between control subjects and patients with growth hormone deficiency (GHD) [6]. In our recent study, we found that by 
western ligand blot analysis, there is no overlap between prepubertal control subjects and patients with complete GHD (cGHD), whereas there is some overlap between these groups during puberty $[11]$.

Recently, using IGFBP-3 RIA, Blum and Ranke reported more than $95 \%$ sensitivity and specificity for diagnosis of GHD [12]. However, Martha et al. and Phillip et al. reported that there was a definite overlap between short children without any hormonal problems and patients with GHD [13,14].

In this study, we measured serum IGFBP-3 levels by RIA in sera from normal children, from normal short children (NS) and from patients with GHD to clarify the utility of IGFBP-3 level as a diagnostic marker for GHD.

\section{Methods and Subjects}

\section{Method}

1) Anti-human IGFBP-3 antisera and purified human IGFBP-3 for iodination were obtained from Dr. W.F. Blum. IGFBP-3 was iodinated and purified by one of us (M.S.), as modified from the method of Blum. A serum standard calibrated to purified IGFBP-3 was used to prepare a standard curve. Five microliters of serum standard, control or unknown were diluted (1:456) with assay buffer before analysis using a dilutor (Compulator, Wheaton Instruments). Serum levels demonstrated parallelism with purified human as well as recombinant human IGFBP-3. The antisera did not cross react with IGF-I, IGF-II, IGFBP-1 or IGFBP-2.

The sensitivity of the assay was $0.3 \mathrm{ng} / \mathrm{m} l$ and half-maximal displacement occurred at $5 \mathrm{ng} / \mathrm{ml}$. After correction for dilution this corresponds to 0.14 and $2.3 \mathrm{mg} / \mathrm{L}$ respectively. The intraassay variation ranged from $8-10 \%$ at $1 \mathrm{mg} / \mathrm{L}$ to $0.9 \%-4 \%$ at $3-4 \mathrm{mg} / \mathrm{L}$. The interassay variation was $16 \%$ at $1 \mathrm{mg} / \mathrm{L}, 11 \%$ at $2 \mathrm{mg} / \mathrm{L}, 6.2 \%$ at 4.5 $\mathrm{mg} / \mathrm{L}$ and $8.6 \%$ at $7.5 \mathrm{mg} / \mathrm{L}$. Measurements were performed in duplicate and in batches of 80 samples by 3 different technicians. To insure the greatest accuracy, samples with initial levels less than $1 \mathrm{mg} / \mathrm{L}$ were repeated at a dilution of 1: 121 .

2) GH was measured by various RIA and IRMA assays. The definition of GHD and NS (defined later) was determined after all the GH levels were converted into our IRMA (Eiken kit) according to the relationships between various $\mathrm{GH}$ assays determined by Japanese Growth Foundation and Tokyo Metropolitan Kiyose Children's Hospital. For example, there was a significant relationship between GH levels by Eiken RIA and those by Eiken IRMA $(\mathrm{GH} \quad \mathrm{IRMA}=0.877 \times$ Eiken RIA-1.39, $\mathrm{r}=0.989, \mathrm{n}=183$ ).

\section{Subjects}

1) Normal control adults ( $n=32$, age $18-40)$ and children $(n=272$, age 1 month-17 years $)$ participated in this study at Tokyo Metropolitan Kiyose Children's Hospital. The heights of the control persons are within the mean $\pm 2 \mathrm{SD}$. Informed consent was obtained at the hospital.

2) Seventy-three patients with GHD (43 complete GHD and 30 partial GHD) and 93 patients with NS (height $<-2$ SD) were also involved in this study. Among them, about $50 \%$ of the patients have been followed up at Tokyo Metropolitan Kiyose Children's Hospital. Among 73 patients with GHD 54 were idiopathic GHD and 19 were secondary GHD due to other diseases such as brain tumor, radiation, etc. The associated hormonal deficiencies were treated appropriately with thyroxine, hydrocortisone and antidiuretic hormone. Secondary hypogonadism was not treated in this study. The definitions of complete GHD (cGHD), partial GHD (pGHD) and NS were the following: cGHD; all the GH peaks of $\mathrm{GH}$ stimulation tests (usually arginine and insulin tolerance tests) are less than $5 \mathrm{ng} / \mathrm{ml}$, pGHD; the highest $\mathrm{GH}$ peaks of GH simulation tests (usually arginine and insulin tolerance tests) are from 5 to $10 \mathrm{ng} / \mathrm{ml}$, NS; at least one $\mathrm{GH}$ peak in $\mathrm{GH}$ simulation tests is more than $10 \mathrm{ng} / \mathrm{ml}$. These definitions of GHD and NS are basically the same as in Blum' and Ranke's paper [12]. GH stimulation tests were done at least twice. IGFBP-3 levels of GHD were measured either before GH therapy was started or after $\mathrm{GH}$ therapy was discontinued. The sera for IGFBP-3 were taken and frozen at -80 or $-120^{\circ} \mathrm{C}$ for at most 1 year until assayed.

\section{Statistics}

Statistical analysis were carried out by Mann- 
Whitney test and Chi-square test. All data are shown as the mean \pm SD.

\section{Results}

1) Figure 1 shows IGFBP-3 levels of normal controls. Table 1 shows the mean $\pm \mathrm{SD}$, normal range, cutoff level for GHD at each age and sex. The normal range was determined after thirteen outlier values (beyond $\pm 2.2 \mathrm{SD}$ ) were omitted from a set of 285 normal children IGFBP-3 values. IGFBP-3 levels less than 2 standard deviations below the mean, at each age were considered to be the cutoff for GHD. There was no significant difference between male and female children. Unlike Blum and Ranke [12], we did not observe

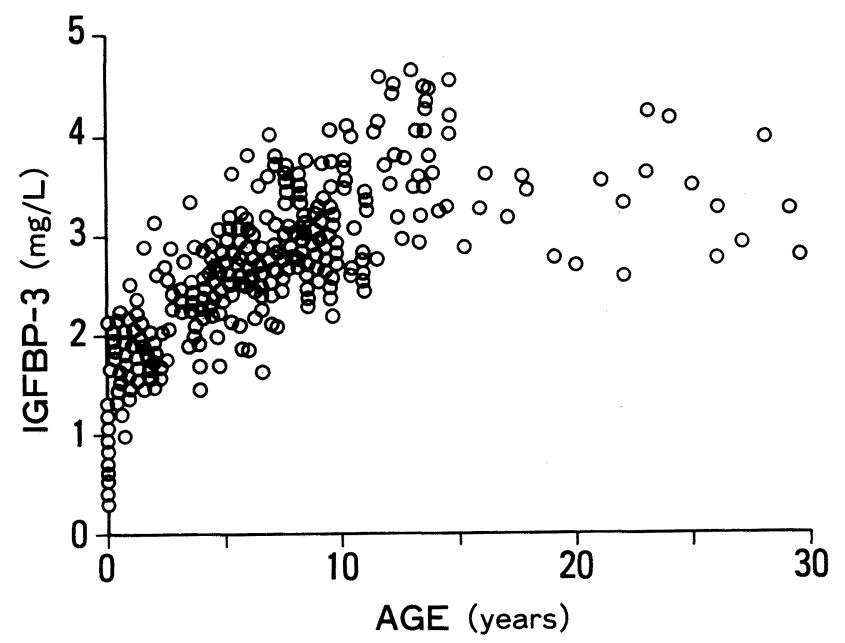

Fig. 1. IGFBP-3 (mg/L) of normal control children.

Table 1. Normal IGFBP-3 (mean \pm SD, range) and cutoff IGFBP-3 levels $(\mathrm{mg} / \mathrm{L})$ for diagnosis of GHD

\begin{tabular}{lrcc}
\hline \multicolumn{1}{c}{ AGE } & \multicolumn{1}{c}{ M \pm SD } & Range & $\begin{array}{c}\text { Cutoff } \\
\text { for } \\
\text { GHD }\end{array}$ \\
\hline $1 \mathrm{~W}-2 \mathrm{Y} ;$ & $1.80 \pm 0.39(\mathrm{n}=58)$ & $0.98-2.91$ & 1.0 \\
$2 \mathrm{Y}-4 \mathrm{Y} ;$ & $2.22 \pm 0.45(\mathrm{n}=32)$ & $1.45-3.35$ & 1.2 \\
$4 \mathrm{Y}-6 \mathrm{Y} ;$ & $2.66 \pm 0.43(\mathrm{n}=41)$ & $1.68-3.85$ & 1.6 \\
$6 \mathrm{Y}-8 \mathrm{Y} ;$ & $\mathrm{M}: 2.67 \pm 0.53(\mathrm{n}=17)$ & $1.60-3.54$ & 1.6 \\
$(\mathrm{M} \& \mathrm{~F})$ & $\mathrm{F}: 3.00 \pm 0.50(\mathrm{n}=29)$ & $2.12-4.03$ & 2.0 \\
$8 \mathrm{Y}-10 \mathrm{Y} ;$ & $\mathrm{M}: 2.98 \pm 0.49(\mathrm{n}=20)$ & $2.28-4.05$ & 2.0 \\
$(\mathrm{M} \& \mathrm{~F})$ & $\mathrm{F}: 3.10 \pm 0.46(\mathrm{n}=19)$ & $2.54-3.80$ & 2.2 \\
$10 \mathrm{Y}-12 \mathrm{Y} ;$ & $3.42 \pm 0.60(\mathrm{n}=23)$ & $2.45-4.58$ & 2.2 \\
$12 \mathrm{Y}-14 \mathrm{Y} ;$ & $3.88 \pm 0.59(\mathrm{n}=23)$ & $2.93-4.62$ & 2.7 \\
$14 \mathrm{Y}-18 \mathrm{Y} ;$ & $3.53 \pm 0.49(\mathrm{n}=11)$ & $2.90-4.55$ & 2.6 \\
$18 \mathrm{Y}-40 \mathrm{Y} ;$ & $3.25 \pm 0.49(\mathrm{n}=33)$ & $2.59-4.26$ & 2.3 \\
\hline
\end{tabular}

M, male; F, female. significantly different IGFBP-3 values in male and female children during puberty.

Among the peri- and post-pubertal normal control children (male; 9-17 years old, female; 8-17 years old), their pubertal stages (Tanner l-V) were recorded in seventy-one children. Normal IGFBP-3 levels for each pubertal stage were determined as follows: Tanner $\mathrm{l} \quad(\mathrm{n}=27)$; $2.97 \pm 0.49 \mathrm{mg} / \mathrm{L}$ (range 1.84-4.05), Tanner II $(\mathrm{n}=15) ; \quad 3.52 \pm 0.60 \mathrm{mg} / \mathrm{L} \quad(2.58-4.5)$, Tanner $\operatorname{III}(\mathrm{n}=13) ; 3.88 \pm 0.68 \mathrm{mg} / \mathrm{L} \quad(2.25-4.62)$, Tanner IV $(\mathrm{n}=10) ; 3.79 \pm 0.52 \mathrm{mg} / \mathrm{L}(3.19-4.55)$, Tanner V $(\mathrm{n}=6) ; 3.84 \pm 0.47 \mathrm{mg} / \mathrm{L}(3.18-4.55)$. There were no significant differences between male and female children at each stage.

2) Figure 2 shows IGFBP-3 levels of patients with CGHD and pGHD. The lines are the cutoff levels for each age as determined above. IGFBP-3 levels of patients with cGHD were almost completely below the cutoff level for each age and sex, whereas a significant number of patients with pGHD had IGFBP-3 levels that were above the cutoff level as stated precisely below.

3) Figure 3 shows IGFBP-3 levels of patients with NS and the cutoff levels for each age and sex. The IGFBP-3 levels of patients with NS were almost always more than the cutoff levels. When we use the control values at each pubertal level for peri- and pubertal patients with NS (male; $>9$ years old, female; $>8$ years old), 4 of 8 patients below the cutoff line in Fig. 3 had IGFBP-3 levels above the puberty-related cutoff level (which was similarly determined to the cutoff level at each age and sex, data not shown).

4) Sensitivity (true positive ratio) and specificity (true negative ratio) were calculated by the results of IGFBP-3 in patients with NS and GHD (Figs. 2 and 3). The sensitivity and specificity were determined based upon whether the IGFBP-3 levels were below or above the age-related cutoff level. The results were expressed separately depending on whether the patients are below or above the age of ten (Table 2). Overall, the specificity and sensitivity for the diagnosis of GHD are 88 and $73 \%$, respectively. When we evaluate the specificity and sensitivity, separately before and after the age of ten, the results are as follows (Table 2): specificity : $87 \%(<10$ years) and $88 \%$ ( $>10$ years); 


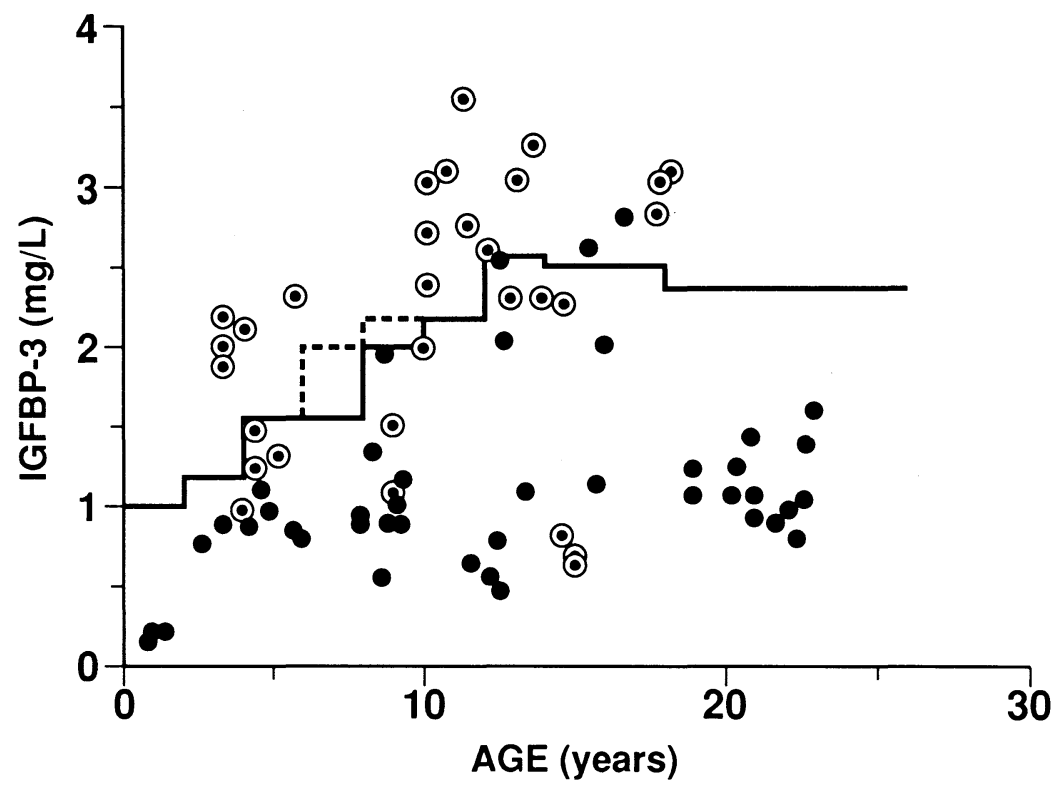

Fig. 2. IGFBP-3 (mg/L) of patients with GHD. The lines are the cutoff level at each age and sex. The dotted line means the cutoff levels for female children only. The closed circle $(\bullet)$ and double circle $(\odot)$ mean cGHD and pGHD, respectively.

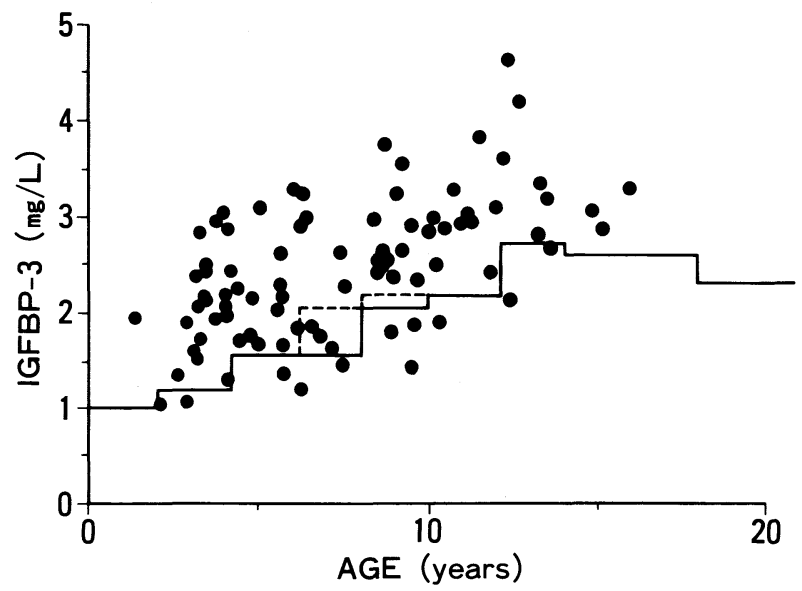

Fig. 3. IGFBP-3 $(\mathrm{mg} / \mathrm{L})$ of patients with NS. The lines are the cutoff level at each age and sex. The dotted line means the cutoff levels for female children only.

sensitivity: $84 \%$ ( $<10$ years), $64 \%$ ( $>10$ years). When cGHD and pGHD are analyzed separately, the sensitivity for GHD is as follows: cGHD: $100 \%$ $(<10$ years) and $88 \%$ (>10 years); pGHD: $58 \%$ $(<10$ years) and 33\% ( $>10$ years) .

5) Among the patients with GHD older than 15 years old, 22 patients were evaluated for secondary hypogonadism. Of these patients, only 1 of 12 with untreated secondary hypogonadism (7
Table 2. Sensitivity and specificity of IGFBP-3

\begin{tabular}{cccc}
\hline & $10 \mathrm{Y}>$ & $10 \mathrm{Y}<$ & total \\
\hline $\begin{array}{c}\text { GHD sensitivity (\%) } \\
\text { (cGHD+pGHD) }\end{array}$ & $\begin{array}{c}84 \% \\
(\mathrm{n}=31)\end{array}$ & $\begin{array}{c}64 \% \\
(\mathrm{n}=42)\end{array}$ & $\begin{array}{c}73 \% \\
(\mathrm{n}=73)\end{array}$ \\
\hline cGHD sensitivity (\%) & $\begin{array}{c}100 \% \\
(\mathrm{n}=19)\end{array}$ & $\begin{array}{c}88 \% \\
(\mathrm{n}=24)\end{array}$ & $\begin{array}{c}93 \% \\
(\mathrm{n}=43)\end{array}$ \\
pGHD sensitivity (\%) & $\begin{array}{c}58 \% \\
(\mathrm{n}=12)\end{array}$ & $\begin{array}{c}33 \% \\
(\mathrm{n}=18)\end{array}$ & $\begin{array}{c}43 \% \\
(\mathrm{n}=30)\end{array}$ \\
\hline NS specificity (\%) & $87 \%$ & $\begin{array}{c}88 \% \\
(\mathrm{n}=69)\end{array}$ & $\begin{array}{c}88 \% \\
(\mathrm{n}=93)\end{array}$ \\
\hline
\end{tabular}

NS, normal short children. Percentage of patients with NS and GHD (cGHD and pGHD) whose IGFBP-3 levels were above and below the cutoff level at each age and sex. The results are shown separately depending on whether the patients are below or above the age of ten.

cGHD and 5 pGHD) had an IGFBP-3 level above the cutoff level. In contrast, out of 10 pubertal patients without secondary hypogonadism (3 cGHD and 7 pGHD), 9 patients showed IGFBP-3 levels above the cutoff level at each age. There is a significant difference between the ratios $(P<0.005)$ for GHD patients with hypogonadism and those without hypogonadism. The IGFBP-3 levels of these GHD patients together with normal levels for each Tanner stage are shown in Fig. 4. 


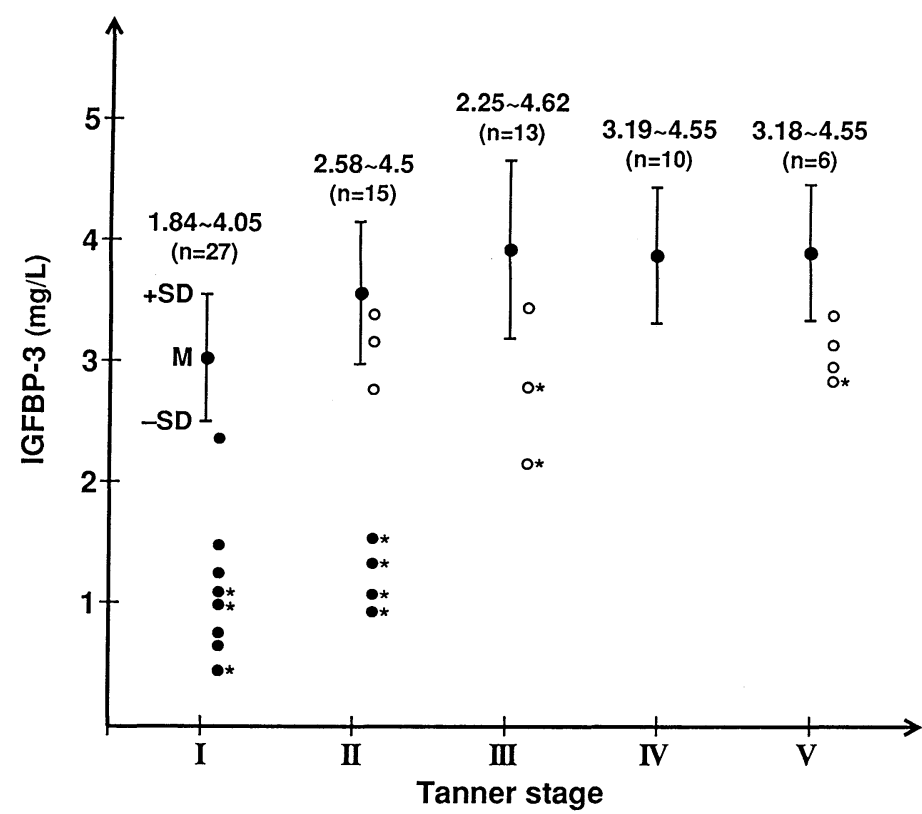

Fig. 4. IGFBP-3 levels (mg/L) of older GHD patients with $(-)$ and without (O) secondary hypogonadism. * represents cGHD. The Tannermatched normal values (mean $\pm \mathrm{SD}$ ) are also shown.

\section{Discussion}

The specificity for diagnosis of GHD was about $90 \%$, which is similar to the results obtained by Blum et al. [12]. The sensitivity for diagnosis of cGHD was more than $90 \%$. Therefore the usefulness of IGFBP-3 measurement for screening GHD was proved.

As shown in Table 2, IGFBP-3 measurement for the diagnosis of pGHD is not so useful as cGHD. The sensitivity for pGHD was much lower than that reported by Blum et al., although they did not classify GHD into two types as we did into cGHD and pGHD. One reason for the difference in the usefulness of IGFBP-3 in cGHD and pGHD is easy to understand: the severity of deficiency is greater in cGHD than in pGHD, by definition. Another possibility is the limitation of GH stimulation tests such as poor reproducibility $[15,16]$ and false positive ratios. We reported that the false positive ratio of arginine and insulin tests in short children was $22-23 \%$ [17].

The difference in the sensitivity between younger $(<10$ years) and older ( $>10$ years) GHD patients may reflect the higher ratio of pGHD to cGHD in the older group. However, two other possibilities may explain the lower sensitivity for GHD after the age of ten: (1) some patients with a constitutional delay in growth and adolescence (CDGA) who had transient GHD [18, 19] were included, although we think this type of transient GHD is not a spectrum of GHD in a true sense but a physiological event. (2) IGFBP-3 levels increase during puberty, independent of the GH-IGF-I axis.

Speculation (1) is likely to be true because we did not perform so-called testosterone or estrogen priming with $\mathrm{GH}$ stimulation tests in necessary cases. In our personal experience (not published), these CDGA patients with transient GHD are usually partial GHD by our definition. Thus, speculation (1) partially explains the fact that the sensitivity of IGFBP-3 testing for pGHD after the age of 10 is lower than that for pGHD before that age. However, we cannot explain the limitation of IGFBP-3 measurement after the age of ten solely by speculation (1), since two patients who were thought to have pGHD and CGHD before GH therapy was started at prepubertal age and who showed IGFBP-3 levels above the cutoff levels at pubertal age, were ascertained to have pGHD and cGHD when GH therapy was discontinued after puberty had developed almost fully.

Speculation (2) is supported by the following fact about GHD patients with or without secondary hypogonadism. Among the twenty-two pa- 
tients with GHD evaluated for secondary hypogonadism, the ratio of patients with GHD whose IGFBP-3 levels were above the age-matched cutoff level for GHD was significantly lower in the patients with GHD associated with secondary hypogonadism than in those without secondary hypogonadism. A similar difference in IGFBP-3 levels between GHD with hypogonadism and that without hypogonadism using the Tanner-matched normal values, as shown in Fig. 4, also supports the speculation (2). This speculation is also consistent with our previous report where we showed an overlap in IGFBP-3 levels on western ligand blot between pubertal control and untreated pubertal or sex-hormone treated (but not treated with GH) pubertal patients with GHD [11]. Furthermore, this speculation is analogous to partial dependence of the serum IGF-1 concentration upon gonadal steroids (independent of $\mathrm{GH}$ ) as reported by Attie and Grumbach [20].

\section{Acknowledgements}

We are greatly indebted for the technical assistance of Dr. F. Kurimoto (Mitsubishi Yuka Bioclinical Laboratories, Tokyo, JAPAN) and Ms. Kelly Dawson (Endocrine Sciences, CA, USA). This work was supported in part by the Sumitomo Pharmaceutical fund (Osaka,JAPAN).

\section{References}

1. Nissley S, Rechler M (1985) Insulin-like Growth Factors: Biosynthesis, Receptors, and Carrier Protein. In: $\mathrm{Li} \mathrm{CH}$ (ed) Hormonal Proteins and Peptides XII. Academic Press, New York: 128-203.

2. Daughaday W, Rotwein P (1989) Insulin-like growth factors I and II. Peptides,messenger ribonucleic acid and gene structures, serum and tissue concentrations. Endo Reviews 10: 68-91.

3. Ballard J, Baxter R, Binoux M, Clemmons D, Drop S, Hall K, Hintz R, Rechler M, Rutanen E, Schwander J (1989) On the nomenclature of the IGF binding proteins. Acta Endocrinologica (Copenh) 121: 751-752.

4. Ballard EJ, Baxter RC, Binoux M, Clemmonce DR, Drop SLS, Hall K, Hintz RS, Ling N, Rechler MM, Rutanen EM, Schwander JC, Spencer EM, Zapf J (1991) On the nomenculature of the IGFBPs. In: Spencer EM (ed) Modern Concepts of Insulin-like Growth Factors: 731-732.

5. Hasegawa Y, Cohen P, Yorgin P, Rosenfeld RG (1992) Characterization of urinary insulin-like growth factor binding proteins. I Clin Endo Metab 74: 830-835.

6. Cohen P, Fielder PJ, Hasegawa Y, Frisch H, Giudice LC, Rosenfeld RG (1991) Clinical aspects of insulin-like growth factor binding proteins. Acta Endocrinol (Copenh) 124: 74-85.

7. Rosenfeld RG, Lamson G, Pham H, Oh Y, Conover C, De Leon DD, Donovon SM, Ocrant I, Giudice L (1991) Insulin-like growth factor binding proteins. Rec Prog Horm Res 46: 99-117.

8. Hardouin S, Gourmelen M, Noguiez P, Seurin D, Roghani M, Bouc YL, Povoa G, Merimee TJ, Hossenlopp MP, Binoux M (1989) Molecular forms of serum insulin-like growth factor binding proteins in man: Relationships with growth hormone and IGFs and physiological significance. $J$ Clin Endocrinol Metab 69: 1291-1301.

9. Hintz R, Liu F, Rosenfeld R, Kemp S (1981) Plasma somatomedin-binding proteins in hypopituitarism: changes during growth hormone therapy. J Clin Endocrinol Metab 53:100-104.

10. Rosenbloom AL, Aguirre JG, Rosenfeld RG, Fielder PJ (1990) The little women of Loja-growth hormone-receptor deficiency in an inbred population of southern Ecuador. $N$ Engl J Med 323: 1367-1374.

11. Hasegawa Y, Hasegawa T, Yokoyama T, Kotoh S, Tsuchiya $Y$, Kurimoto F (1992) Western ligand blot-assay for human growth hormone-dependent insulin-like growth factor binding protein (IGFBP3)-The serum levels in patients with classical growth hormone deficiency. Endocrinol Japon 39: 121-127.

12. Blum WF, Ranke MB, Kietzmann K, Gauggel E, Zeisel HJ, Bierich JR (1990) A specific radioimmunoassay for the growth hormone-dependent somatomedin-binding protein: Its use for diagnosis of GH deficiency. J Clin Endocrinol Metab 70: 1292-1298.

13. Martha PM, Reiter EO, Blizzard RM, Stene M, Veldhuis JD, Rogol AD (1991) The maturityrelated rise of IGFBP-3 concentration. Pediatric Research (Abstract) 473: 81A.

14. Phillip M, Chalew SA, Kowarski AA, Stene M (1991) Insulin-like growth factor-binding protein 3 concentrations in poorly growing children: relationship with quantitative growth hormone srcretion and response to GH therapy. Pediatric Research (Abstract) 460: 145.

15. Donaldson DL, Pan F, Hollowell JG, Stevenson JL, 
Gifford RA, Moore WV(1991) Reliability of stimulated and spontaneous growth hormone $(\mathrm{GH})$ levels for identifying the child with low GH secretion. J Clin Endocrinol Metab 72: 647-652.

16. Hasegawa Y, Hasegawa T, Kotoh S, Tsuchiya Y. Reproducibility of GH stimulation tests (arginine and insulin), IGF-I levels and IGFBP-3 levels Clinical Pediatric Endocrinology (in print).

17. Hasegawa $Y$, Hasegawa $T$, Kotoh S, Tsuchiya Y. Ratio of false positive results of $\mathrm{GH}$ stimulation tests (arginine and insulin) Clinical Pediatric Endocrinology (in print).
18. Bierich JR (1986) Treatment by hGH of constitutional delay of growth and adolescence. Acta Pediatr Scandina 325 [Suppl]: 71-75.

19. Bierich JR (1983) Treatment of constitutional delay of growth and adolescence with human growth hormone. Klin Paediat 195: 309-316.

20. Attie KM, Ramirez NR, Conte FA, Kaplan SL, Grumbach MM (1990) The pubertal growth spurt in eight patients with true precocious puberty and growth hormone deficiency: Evidence for a direct role of sex steroids. J Clin Endocrinol Metab 71: 975-983. 